\title{
Conceptualizing diseases
}

\author{
Cite as: CMAJ 2019 May 6;191:E507-8. doi: 10.1503/cmaj.181629
}

CMAJ Podcasts: author interview at https://soundcloud.com/cmajpodcasts/181629-medsoc

hysicians talk about diseases all the time, whether in the abstract, when discussing the presentation or treatment of a given diagnosis, or in the particular, when giving a diagnosis to a patient. Yet, the remarkable fact is that we cannot easily say what diseases are. What is their nature? Are they part of the furniture of the world, like electrons, or something humans create, like countries? And regardless, what are they made of?

An equally troubling question is, what does it mean to categorize something as a "disease?" Why is tuberculosis a disease? It may seem obvious, but explaining why is difficult. Some apparently plausible answers may also require one to consider pregnancy or homosexuality as diseases. Other answers may rule out hypertension as a disease. The trick is explaining why all and only the "right" conditions are indeed diseases. ${ }^{1}$ I mention this problem to avoid confusion (and provoke further curiosity). The question "What is disease?" is a topic for a separate article. The questions now are, what is the nature of a particular disease and of what do diseases consist?

Responses to these questions fall into 2 categories: realism and constructivism. ${ }^{2,3}$ Consider a patient who presents with cough, fever and malaise for a week and foot pain for 2 months. The physician's first job is to figure out which of these complaints form a single disease. The foot pain is of longer duration and likely unrelated to the other symptoms, so the physician will probably decide that the cough, fever and malaise constitute the patient's acute disease. The next question is, what disease is this - influenza, an upper respiratory infection or pneumonia? Only by

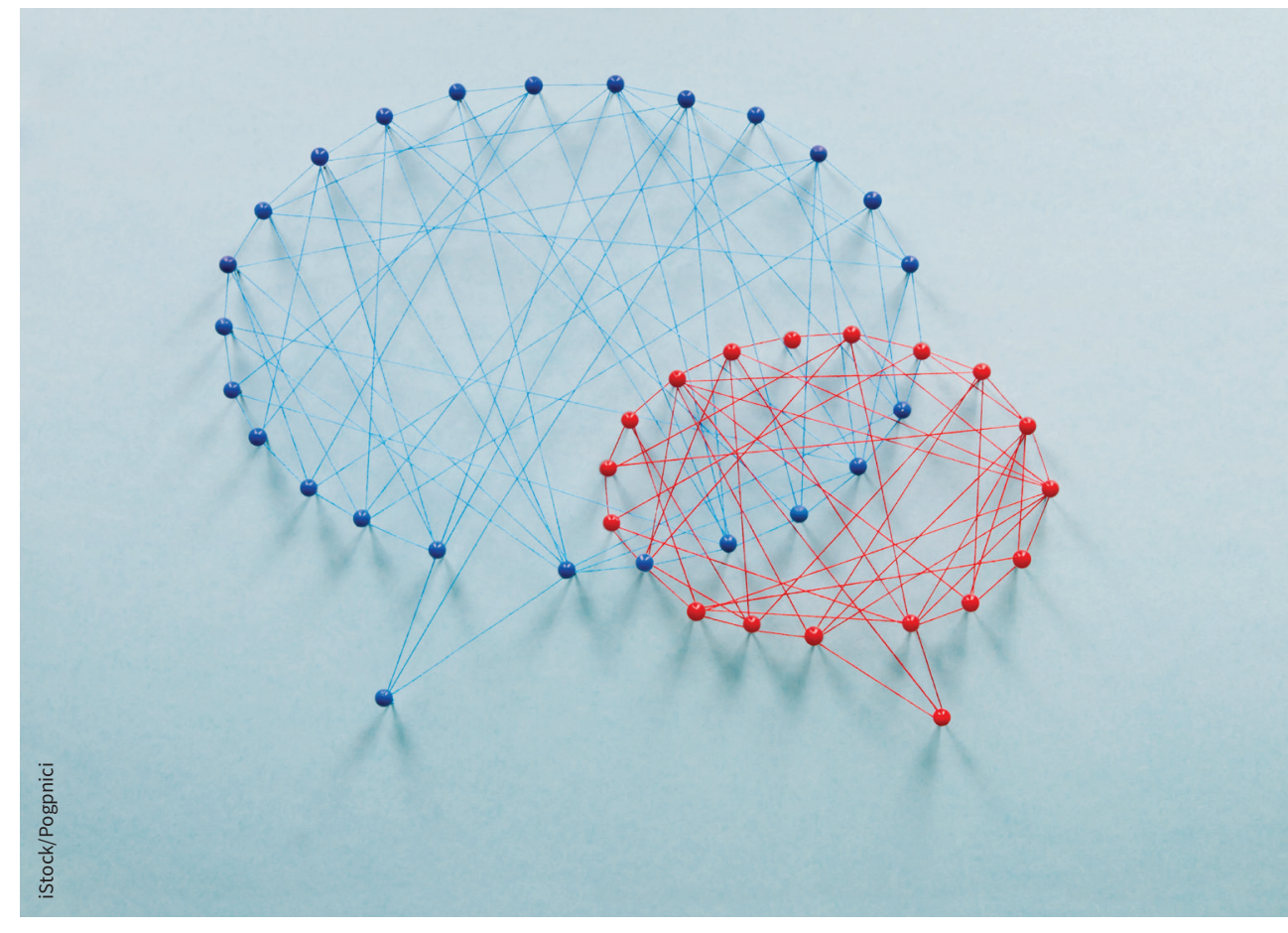

appropriately answering both questions can the physician supply appropriate treatment and prognosis. This distinction, between the particular instance of disease that a patient has and the diagnosis to which it belongs, can be difficult to keep track of, as "disease" refers to both. They can be kept distinct by referring to them, in this context, as "disease" and "diagnosis," respectively.

Realists and constructivists disagree about what is going on at both steps. Regarding diseases, realists believe that some sort of physical entity (roughly speaking) determines whether the physician is correct in delineating the extent of the disease, just as there is a correct answer as to whether a given limb is part of this or that person. A realist will then say that whether or not 2 patients have the same diagnosis is determined by the outside world, just as is the question of whether 2 elementary particles are the same (e.g., 2 electrons) or different (e.g., an electron and a photon). ${ }^{2,3}$ In the language of philosophy, groupings that are imposed by the outside world are called "natural kinds." 4 Thus, diagnoses are natural kinds for a realist.

Constructivists do not believe that the identification of diseases and diagnoses is determined by the natural world. Rather, they believe that in identifying the components of a patient's disease, the physician is making a choice. The choice can be better or worse, but there is no absolute sense in which it can be correct. Identifying the different diagnoses is likewise a choice that can be better or worse, albeit a choice that takes place not during an encounter with an individual patient but at a higher level. $2,3,5,6$ 
At this point, I expect that some readers are thinking that diseases and diagnoses are obviously real, whereas others are thinking that they are obviously constructed. It is therefore important to note that there are strong intuitions and arguments behind each position. Certainly, a scientist who says, "I am studying glioblastoma to develop a cure" seems to be saying something as real as a scientist who says "I am studying photons to figure out how to make a new type of laser." Furthermore, our success at developing new treatments makes it seem like there are entities out there that we learn to control better as we discover more about them.

On the other hand, anyone who has taken care of patients cannot fail to be struck by the often vast differences between 2 patients with the same diagnosis. Are 2 cases of cystic fibrosis really the same in the same way that 2 electrons are? What does it mean to say that diseases are out there in the world ready to be found in the patient? What sort of thing are they? There is nothing you can hold and point to as a disease, the way you can hold a cat or even, in a way, an electron.

Let us consider in more detail what realists and constructivists think. First, what is the nature of the entities that constitute an individual patient's disease according to the realist? There are 3 main approaches. Realist philosophers have understood diseases as bundles of signs and symptoms, as parts of the underlying microstate of the patient or as a process the patient is undergoing. Consider insulin-dependent diabetes. If diseases are a bundle of signs and symptoms, then to have insulin-dependent diabetes is to have, for example, high blood glucose and frequent urination. If diseases are an underlying state of a person, then having insulin-dependent diabetes is being in a state of low insulin production (and perhaps some related changes). To understand insulin-dependent diabetes as a process (somewhat more difficult to articulate), the focus would be on the processes of metabolizing (or not) various energy sources and the ongoing effects this has on the body. Moving on to the level of diagnoses is relatively easy for the realist, as realists agree that diseases belong to natural kinds. ${ }^{2,3}$

For constructivists, a disease is merely signs, symptoms and study results in the patient that are grouped by a physician taking into consideration which diagnoses might fit the patient's symptoms. The interesting question is, where do the choices of diagnoses come from? Someone is deciding the criteria for various diagnoses, but who, and how? Each of these questions has several potential answers. Regarding who, the most straightforward answer is physicianscientists, but other possibilities include the government, business interests or patient interest groups. Obviously, none of these other groups directly sets criteria, but a constructivist could argue that when physicians promulgate criteria, they are doing so at the (possibly hidden) direction of one of these other groups. ${ }^{2,3}$

How the responsible parties make these decisions, that is, by what criteria, likewise has several possibilities. One possibility is that diagnoses are recognized to help maximize our understanding of the world. This is superficially like the realist position, except that there are no right or wrong answers here, just tools that seem more or less useful to scientists, subject to revision as needed. Other possibilities are that diagnoses are identified to maximize the well-being of those who seek medical care, the wealth of certain groups or the political power of an elite. All of these positions have been proposed. ${ }^{2,3}$

To a philosopher, the nature of diseases and diagnoses is an interesting topic for its own sake. However, the question has potential ramifications for clinical practice. If the realists are correct, then we can study and treat only the diagnoses that nature has given us. Once we have done that, we can use this knowledge to help people. But the science is conceptually primary, and physicians can only help patients by identifying and learning about real diagnoses. If, however, there are no real diagnoses, just constructed groupings of ill people, then it may be reasonable for those who study and treat diseases to consider the best way to group patients. Who should do it, and based on what? What will allow medicine to do the most good? ${ }^{7}$

For centuries, these questions did not matter, because medicine could do relatively little to help people. Now that scienific enquiry increasingly informs our understanding of how to treat people, it is imperative that physicians understand what we are doing so that we can best direct our efforts.

\section{Jeremy R. Simon MD PhD}

Department of Emergency Medicine, Columbia University, New York, NY

\section{References}

1. Boorse C. Concepts of health and disease. In: Gifford F, editor. Philosophy of medicine. Vol 16. Amsterdam: Elsevier Science; 2011:13-64.

2. Simon JR. Medical ontology. In: Gifford F, editor Philosophy of medicine. Vol 16. Amsterdam: Elsevier Science; 2011:65-114

3. Simon JR. Realism and constructivism in medicine. In: Solomon M, Simon JR, Kincaid H, editors. The Routledge companion to philosophy of medicine. New York: Routledge; 2016:90-100.

4. Kukla A. Studies in scientific realism. New York: Oxford University Press; 1998.

5. Kukla A. Social constructivism and the philosophy of science. New York: Routledge; 2000.

6. Hacking I. The social construction of what? Cambridge (MA): Harvard University Press; 2000.

7. Simon JR. Advertisement for the ontology of medicine. Theor Med Bioeth 2010;31:333-46.

This article was solicited and has been peer reviewed. 